\title{
Effect of feeding frequency on growth, feed utilisation and cannibalism in climbing perch Anabas testudineus (Bloch 1792) fry
}

\author{
LIPSHA DASH, RAJESH KUMAR, KEDAR NATH MOHANTA, UTKAL LAXMI MOHANTY, \\ BINDU R. PILLAI AND JITENDRA KUMAR SUNDARAY \\ ICAR-Central Institute of Freshwater Aquaculture, Kausalyaganga, Bhubaneswar - 751 001, Odisha, India \\ e-mail: rajeshfishco@yahoo.co.uk
}

\begin{abstract}
A 35 days experiment was conducted to study the effect of different feeding frequencies on growth and feed utilisation in climbing perch Anabas testudineus (Bloch 1792) fry. Four different feeding frequencies in triplicate viz., $2\left(\mathrm{~T}_{1}\right), 3\left(\mathrm{~T}_{2}\right)$, $4\left(\mathrm{~T}_{3}\right)$ and $5\left(\mathrm{~T}_{4}\right)$ times a day were evaluated. Fry (144 nos.) of climbing perch were randomly distributed in 12 glass aquaria (50 1) containing 251 of filtered and well aerated freshwater. Formulated pellet feed was prepared and fed @ 6\% body weight to all the experimental groups at different feeding frequencies as mentioned above. At the end of the experiment, fishes were sampled to determine weight gain percentage (WG \%), specific growth rate (SGR), food conversion ratio (FCR), protein efficiency ratio (PER), survival percentage (\%) and partial cannibalism rate (\%). Results revealed that the WG\% (112.80 \pm 2.25$)$, PER $(1.65 \pm 0.03)$ and SGR $(2.15 \pm 0.03)$ were significantly higher $(\mathrm{p}<0.05)$ in $\mathrm{T}_{3}$ group. FCR $(1.55 \pm 0.03)$ was lowest in $\mathrm{T}_{3}$ group. Partial cannibalism rate $(\%)$ was significantly higher $(\mathrm{p}<0.05)$ in the treatment group $\mathrm{T}_{1}(6.33 \pm 0.88)$ whereas the survival rate (\%) was lowest in $T_{1}(91.66 \pm 4.81)$ The results therefore, indicated that feeding frequency of 4 times a day $\left(\mathrm{T}_{3}\right)$ could be the ideal feeding frequency for better growth and feed utilisation during fry rearing of climbing perch.
\end{abstract}

Keywords: Anabas testudienus, Cannibalism, Climbing perch, Feeding frequency, Food conversion ratio, Growth

The climbing perch, Anabas testudineus (Bloch 1792) is one of the important indigenous air-breathing fish in India with high market price (₹300-500 $\mathrm{kg}^{-1}$ ) in the states of Assam, Bihar, Jharkhand, Odisha, Manipur, Tripura and West Bengal (Kumar et al., 2013a). It is popularly known as 'kavai' in Hindi, 'kou' in Odisha, 'koi' in West Bengal and 'kai' in Assam. It has a wide range of geographical distribution due to its exceptional physiological adaptation with respect to air breathing habit and salinity tolerance (Kumar et al., 2012). This fish, due to its air breathing ability and tolerance to extremely unfavourable environmental conditions, is a prominent candidate fish for aquaculture (Sarkar et al., 2005). The possession of accessory respiratory organs enable the species to be farmed at high stocking density (Anantharaja et al., 2017). The fish contains very high amount of physiologically available iron and copper required for haemoglobin synthesis (Kumar et al., 2013b); as well as essential amino acids and easily digestible polyunsaturated fatty acids (Zalina et al., 2012). Due to its air breathing ability and tolerance to adverse environmental conditions, it is a good candidate fish for climate resilient aquaculture.

Feed plays a vital role for culture of any fish species. The larval and young fry stages are very much dependent on the feed supplied to them. Most fish in fry stage do not accept any formulated feed given initially, but after some days they start accepting the feed, if other conditions of rearing are properly maintained (Watanabe et al., 1983). In case of climbing perch, larvae and young fry feed on phytoplankton and zooplankton and adults feed on crustaceans, worms, insects, algae, soft higher plants as well as organic debris. Sufficient literature is available on feeding of fry of carps and cat fishes (Lovell and Stickney, 1977; Debrowskie et al., 1987; Marte et al., 1991). Till date there is scanty information available on feeding as well as feeding frequency of climbing perch fry. As the breeding protocol for climbing perch using exogenous hormone (GnRHa) has been standardised (Mandal et al., 2016), it is necessary to have knowledge on the proper feeding frequency for mass production of climbing perch seed and also to enhance their growth and feed utilisation. Therefore, the present study was carried out to evaluate the role of different feeding frequencies on growth, feed utilisation and cannibalism in climbing perch fry.

The experiment was conducted over a period of five weeks (35 days) at the Air-breathing Fish Breeding and Culture Unit of Aquaculture Production and Environment Division, ICAR-Central Institute of Freshwater Aquaculture 
(ICAR-CIFA), Bhubaneswar, Odisha. The biochemical analysis of the test diet was conducted in the laboratory of Fish Nutrition and Physiology Division, ICAR-CIFA.

Animals used for experimental purpose were the hatchery produced climbing perch fry of an average individual weight of $0.225 \pm 0.02 \mathrm{~g}$. An indoor rearing system was utilised for the study. The system consisted of 12 glass aquaria of 501 capacity holding 251 seasoned bore well water. The tanks were divided into four treatments based on feeding frequency viz., treatment $\mathrm{T}_{1}(2$ times a day) $\mathrm{T}_{2}$ ( 3 times a day), $\mathrm{T}_{3}$ (4 times a day) and $\mathrm{T}_{4}$ (5 times a day), each having three replicates. One hundred forty four fry of climbing perch were randomly distributed in 12 tanks@12 fry per tank. Before starting the experiment, the tanks were disinfected with potassium permanganate solution $\left(\mathrm{KMnO}_{4}\right)$. All the tanks were cleaned and siphoned every day in the morning before feeding the fry, and replenished with clean and seasoned bore well water to maintain water level in the tank.

Ingredients such as fish meal, soyabean meal, groundnut oil cake (GNOC), maize flour, fish oil, vitamin-mineral mixture (Kalvimin Forte) and carboxy methyl cellulose (CMC) were used for feed preparation. All the required ingredients were weighed accurately in an electronic balance (Table 1). All the dry ingredients except vitamin-mineral mix were mixed manually to form homogeneous mixture. Then water was added to form dough and the dough was wrapped in a wet cloth and transferred to an aluminum container which was then placed in a pressure cooker for steaming for half an hour. The steamed dough was taken out and cooled further and to this vitamin-mineral mixture along with fish oil were added and mixed properly. The dough was then pressed through a hand pelletiser to get uniform size pellets and was initially fan dried on a polythene sheet. The feed was then transferred to a tray and kept in a hot air oven overnight for complete drying at $50-60^{\circ} \mathrm{C}$ and later crumbled manually, packed in an airtight jar and labeled according to the treatment.

The proximate composition of experimental diet was analysed by AOAC (1990) method. Dry matter was estimated by oven drying the samples at $105^{\circ} \mathrm{C}$ overnight. Crude protein percent was calculated by estimating nitrogen content by micro-Kjeldahl method and multiplying with a factor 6.25. Ether extract was determined by solvent extraction with petroleum ether, at 40-60 $\mathrm{C}$, for $10-12 \mathrm{~h}$. Total ash content was determined by incinerating the sample at $650^{\circ} \mathrm{C}$ for $6 \mathrm{~h}$ and crude fiber by acid digestion $(1.25 \%)$ followed by alkali digestion $(1.25 \%)$.

Gross energy in the diet was calculated using Bomb Calorimeter (Parr, model 1341; Parr Instrument Company, Moline, IL, USA). The ingredients composition and proximate composition of the test diet are shown in Table 1.

After acclimatisation in the experimental tanks, A. testudineus fry were fed manually with the test diet at $6 \%$ of their total body weight at different feeding frequencies such as $\mathrm{T}_{1}-2$ times a day (at 08:00 and 17:00 hrs), $\mathrm{T}_{2}-3$ times a day (at 08:00, 12:00 and 17:00 hrs), $\mathrm{T}_{3}-4$ times a day (at 08:00, 11:00, 13:00 and 17:00 hrs) $\mathrm{T}_{4}-5$ times a day (at 08:00, 11:00, 13:00, 15:00 and 17:00 hrs).

For the fish in each experimental group, the means of weight gain\% (WG\%), specific growth rate (SGR), food conversion ratio (FCR), protein efficiency ratio (PER) and survival rate were calculated as: weight gain \% $(\mathrm{WG} \%)=W_{f}-W_{i} / W_{i}^{*} 100$ where $W_{i}$ and $W_{f}$ are the initial and final weight of all fish in each glass aquaria. $\mathrm{SGR}=\left[\left(\ln W_{f}-\ln W_{\mathrm{i}}\right), \mathrm{t}\right]^{*} 100$, where $t$ is the number of experimental days. FCR $=$ Feed given/Weight gain of animal. PER $=$ Gain in body mass $(\mathrm{g}) /$ Protein intake $(\mathrm{g})$.

Table 1. Ingredient and proximate composition of the test diet

\begin{tabular}{lllll}
\hline \multicolumn{1}{c}{ Ingredient composition of the test diet } & & \multicolumn{2}{c}{ Proximate composition of the test diet } \\
\cline { 1 - 1 } Ingredients & $\%$ (Dry matter) & & Nutritional parameters & Proximate composition (\%) \\
\hline Fish meal & 40 & & Dry matter & 94.3 \\
Ground nut oil cake & 20 & & Crude protein & 39.15 \\
Soya bean meal & 15 & & Ether extract & 7.13 \\
Maize flour & 20 & & Crude fiber & 9.81 \\
Carboxy methyl cellulose & 1 & & Ash & 10.15 \\
Vitamin-mineral mix. & 2 & & Nitrogen free extract & 43.57 \\
Fish oil & 2 & & Energy (k cal g $\left.{ }^{-1}\right)$ & 39.76 \\
\hline
\end{tabular}

*Vit. A - 2,00,000 IU, Vit. B2 - 80 mg, Vit. B12 - 0.24 mg, Vit. D3 - 40,000 IU, Vit. E - 32 IU, Calcium pantothenate -160 mg, Calcium - 32 g, Phosphorous - 6 g, Manganese - 1.1g, Iodine - 40 mg, Iron - 300 mg, Zinc - 600 mg, Copper - 80 mg, Cobalt - 20 mg 
After completion of the feeding experiment, the survival rate of climbing perch fry was calculated as: Total number of fry survived/Total number of fry stocked * 100 .

In this experiment, partial cannibalism was encountered among the fry of different experimental groups. Generally in partial cannibalism, cannibals attack the pectoral fin, caudal fin, abdomen region and the eyes of the prey.

Water quality parameters estimated (APHA, 1992) during the experimental period were: temperature 23.0-28. $0^{\circ} \mathrm{C}$; $\mathrm{pH}$ - 7.4-7.6; alkalinity - 108-136 $\mathrm{mg} \mathrm{l}^{-1}$; hardness - 104-144 $\mathrm{mg} \mathrm{l}^{-1}$; dissolved oxygen - 4.0-6.0 $\mathrm{mg} \mathrm{l}^{-1}$; ammonia - 0.02-0.1 $\mathrm{mg} \mathrm{l}^{-1}$; nitrite - 0.03-0.06 $\mathrm{mg} \mathrm{l}^{-1}$ and nitrate $-0.1-0.3 \mathrm{mg} \mathrm{l}^{-1}$.

All the data were analysed using one-way analysis of variance (ANOVA) using SPSS V. 15 software followed by use of Duncan's new multiple range tests to compare differences at $\mathrm{p} \leq 0.05$ level. Results are presented as means \pm standard error of the mean.

At the end of the experimental period of 35 days $\mathrm{WG} \%$ in $A$. testudineus fry was highest $(\mathrm{p}<0.05)$ in $\mathrm{T}_{3}$ group $(112.88 \pm 2.25 \%)$ and lowest in $\mathrm{T}_{4}$ group $(83.61 \pm 1.13 \%)$. Similarly SGR was highest $(\mathrm{p}<0.05)$ in $\mathrm{T}_{3}$ $(2.15 \pm 0.03)$ group compared to other treatment groups (Table 2). The FCR was lowest in the treatment group $\mathrm{T}_{3}$ $(1.55 \pm 0.03)$ whereas it was highest in $\mathrm{T}_{2}(2.187 \pm$ 0.08 ). PER is widely used for evaluating the quality of protein in the feed. PER was highest in $\mathrm{T}_{3}$ group (1.65 \pm 0.03 ) in comparison to other treatment groups (Table 2). In the treatment groups $T_{3}$ and $T_{4}$, survival rate of the climbing perch fry was $100 \%$ whereas in the treatment group $T_{1}$ and $T_{2}$, survival rate was $91.66 \%$ and $97.22 \%$, respectively (Table 2 ).

The growth and survival of fish larvae/fry are highly influenced by feed given to them. For successful culture of any fish, suitable feed is one of the most important prerequisites. Non-availability of quality feed is one of the vital factors that affect commercial fish culture. In the present study, the test feed was prepared from locally available ingredients. The test diet had 39.15\% crude protein and it was prepared based on the nutrient requirement of this species at fry stage (Hossain et al.,
2012). Better weight gain percentage, FCR and SGR were observed in $\mathrm{T}_{3}$ group where feeding frequency was 4 times a day. Growth and production of fish generally depend on the daily feed consumption, quality of feed and feeding frequency, (Mookerjee and Mazumdar, 1946). In the present study, growth of fishes increased with feeding frequency and the best growth was observed in group where feeding frequency, was 4 times a day ( $T_{3}$ group) and beyond this feeding frequency, growth performance reduced. This result is in agreement with James and Sampath (2004) who found growth enhancement in Betta splendens when fed three times daily for 77 days. Meer et al. (1997) reported that red pacu, Colossoma macropomum fed five times a day showed better growth and nutrient utilisation.

In this study, SGR was significantly higher $(\mathrm{p}<0.05)$ in $T_{3}$ group where feeding frequency was 4 times a day and lowest in $\mathrm{T}_{4}$ group where the experimental animals were fed @ 5 times a day. PER was also highest in $\mathrm{T}_{3}$ group in comparision to other treatment groups. Doolgindachabaporn (1994) found that FCR in A. testudineus ranged from 1.8-3.0. Potongkam (1972) reported that FCR of climbing perch fed on trash fish and pellet were 2.07 and 1.89 respectively. In this study, FCR was lowest in $\mathrm{T}_{3}$ group (1.55 \pm 0.03$)$ which indicates better feed utilisation efficiency.

Carlos (1988), Chua and Teng (1978) and Goldan et al. (1997) showed that feeding frequency had significant effect on the survival rate of different fish species such as Aristichthys nobilis, Epinephelus tauvina and Sparus aurata. Mookerjee and Mazumdar (1946) in a study with climbing perch with prepared feeds (containing 35-45\% protein) observed survival rate ranging from $75-89 \%$. Doolgindachabaporn (1994) also recommended that the feed containing $38.6 \%$ protein as the best feed formula in terms of growth and survival for Anabas fry. Mookerjee and Mazumdar (1946), tested the performance of different diets containing 30, 34.7, 39.5, 44.1 and 48.9\% protein on dry weight basis and reported that $39.5 \%$ protein is optimum in the diet for commercial rearing of A. testudineus. Climbing perch is an excellent candidate for aquaculture as this species can adapt itself and if necessary can change its preference to certain food items,

Table 2. Effect of different feeding frequencies on growth and other nutritional parameters of Anabas testudineus fry

\begin{tabular}{lllllllll}
\hline Treatments & Initial weight $(\mathrm{g})$ & Final weight $(\mathrm{g})$ & Weight gain $(\mathrm{g})$ & WG $\%$ & SGR & FCR & PER & Survival rate $(\%)$ \\
\hline $\mathrm{T}_{1}$ & $2.63 \pm 0.0^{\mathrm{a}}$ & $4.83 \pm 0.0^{\mathrm{b}}$ & $2.20 \pm 0.0^{\mathrm{b}}$ & $83.95 \pm 2.88^{\mathrm{b}}$ & $1.74 \pm 0.0^{\mathrm{b}}$ & $2.01 \pm 0.16^{\mathrm{b}}$ & $1.29 \pm 0.0^{\mathrm{b}}$ & $91.66 \pm 4.81$ \\
$\mathrm{~T}_{2}$ & $2.67 \pm 0.0^{\mathrm{a}}$ & $4.82 \pm 0.0^{\mathrm{b}}$ & $2.14 \pm 0.0^{\mathrm{b}}$ & $89.44 \pm 7.46^{\mathrm{b}}$ & $1.82 \pm 0.1^{\mathrm{b}}$ & $2.187 \pm 0^{\mathrm{b}}$ & $1.17 \pm 0.0^{\mathrm{b}}$ & $97.22 \pm 2.78$ \\
$\mathrm{~T}_{3}$ & $2.80 \pm 0.0^{\mathrm{a}}$ & $5.96 \pm 0.0^{\mathrm{a}}$ & $3.16 \pm 0.0^{\mathrm{a}}$ & $112.80 \pm 2.2^{\mathrm{a}}$ & $2.15 \pm 0.03^{\mathrm{a}}$ & $1.55 \pm 0.03^{\mathrm{a}}$ & $1.65 \pm 0.03^{\mathrm{a}}$ & 100 \\
$\mathrm{~T}_{4}$ & $2.76 \pm 0.07^{\mathrm{a}}$ & $5.07 \pm 0.16^{\mathrm{b}}$ & $2.31 \pm 0.09^{\mathrm{b}}$ & $83.61 \pm 1.13^{\mathrm{b}}$ & $1.73 \pm 0.01^{\mathrm{b}}$ & $2.09 \pm 0.03^{\mathrm{b}}$ & $1.22 \pm 0.02^{\mathrm{b}}$ & 100 \\
\hline
\end{tabular}

Values in the same column with different superscripts differ significantly $(\mathrm{p}<0.05)$ 
depending on the availability of items in a particular environment. In this study, mortalities occurred during the last phase of the experiment because of the injuries caused by partial cannibalism in lower feeding frequency groups. But this problem was negligible in groups where feeding frequency was more. During the experimental period, water quality was monitored at weekly intervals and found to be in ideal range for the growth of climbing perch fry.

Partial cannibalism was highest in the treatment group $T_{1}$ where the fry were fed 2 times a day and lowest in the treatment group $\mathrm{T}_{4}$ where feeding frequency was 5 times a day. However, in the treatment groups $\mathrm{T}_{3}$ and $\mathrm{T}_{4}$ partial cannibalism was minimal (Fig.1).

Cannibalism is considered as one of the major problem under high density fish culture since the mid-1970s. Larval and juvenile sibling cannibalism occur

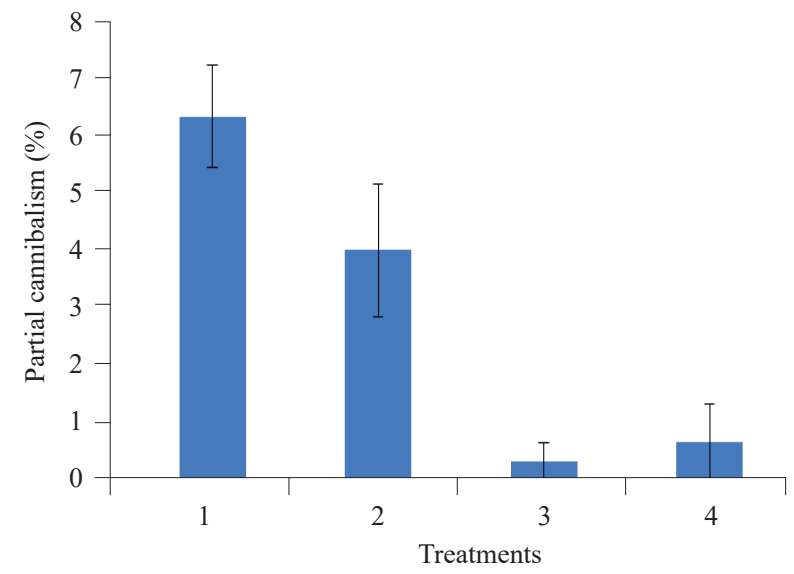

Fig. 1. Effect of different feeding frequencies on partial cannibalism of A. testudineus fry

in important cultured species such as yellowtail (Seriola quinqueradiata), turbot (Scophthalmus maximus), eels (Anguilla anguilla), seabass (Dicentrarchus labrax) and gilthead bream (Sparus aurata) (Chaudhuri and Tripathi, 1979; Smith, 1979; Kentouri, 1980; Degani and Levanon, 1983). Cannibalism is a behaviour manifested under conditions of food shortage. In larvae and fry rearing stage main cause of cannibalism is associated to food availability. Katavic et al. (1989) reported that cannibalism can be reduced by increasing the feeding frequency. The inverse relationship between the feeding rate and cannibalism is also reported in Gadus morhua (Folkvord, 1991). In the present study, partial cannibalism in climbing perch fry was highest where feeding frequency was low i.e., 2 times a day and lowest in the treatment group where feeding frequency was more i.e. 4 times a day. In several fish species, including Clarias gariepinus, a decrease in cannibalism has been reported with increased food availability (Fox,
1975; Polis, 1981; Hecht and Pienaar, 1993). A similar trend has been shown for other cultured marine finfish including greater amberjack, Seriola dumerili (Miki et al., 2011) and Japanese flounder, Paralichthys olivaceus (Dou et al., 2000). However, partial cannibalism could be controlled by increasing feeding frequency and suitable size grading during seed rearing.

In conclusion, feeding frequency of 4 times a day was found optimal for better growth and feed utilisation in climbing perch fry. Further, at this feeding frequency cannibalism was also minimum and therefore, it is suggested to feed climbing perch fry 4 times a day for better growth and survival during seed rearing.

\section{Acknowledgements}

The authors express their deep sense of gratitude to the Director, ICAR-CIFA, Bhubaneswar, for providing necessary facilities, constant encouragement and support to carry out the research work.

\section{References}

AOAC 1990. Official methods of analysis, $15^{\text {th }}$ edn. Association of Official Analytical Chemists, Arlington, USA.

APHA 1992. Standard methods for the examination of water and waste water. American Public Health Association, Washington, DC, USA, 1134 pp.

Anantharaja, K., Mohapatra, B. C., Pillai, B. R., Kumar, R., Devaraj, C. and Majhi, D. 2017. Growth and survival of climbing perch, Anabas testudineus in Nutrient Film Technique (NFT) Aquaponics System. Int. J. Fish. Aquat. Stud., 5(4): 24-29.

Carlos, M. H. 1988. Growth and survival of bighead carp (Aristichthys nobilis) fry fed at different intake levels and feeding frequencies. Aquaculture, 68(3): 267-276. doi.org/10.1016/0044-8486(88)90358-4.

Chaudhuri, H. and Tripathi, S. D. 1979. Problems of fish seed production. In: Pillay, T. V. R. and Wm. A. Dill (Eds.), Advances in aquaculture, Fishing News Books, p. 127-134.

Chua, T. and Teng, S. 1978. Effects of feeding frequency on the growth of young estuary grouper, Epinephelus tauvina (Forskål), cultured in floating net-cages. Aquaculture, 14(1): 31-47. doi.org/10.1016/0044-8486(78)90138-2.

Dabrowski, K., Kaushik, S. J. and Fauconneau, B. 1987. Rearing of sturgeon (Acipenser baeri Brandt) larvae: III. Nitrogen and energy metabolism and amino acid absorption. Aquaculture, 65: 31-41. doi.org/10.1016/00448486(87)90268-7.

Degani, G. and Levanon, D. 1983. The influence of low density on food adaptation, cannibalism and growth of eels (Anguilla anguilla L.). Israeli J. Aquac., Bamidgeh, 35: 53-60. 
Doolgindachabaporn, S. 1994. Development of optimal rearing and culturing system for Climbing perch, Anabas testudineus (Bloch). Ph. D. Thesis, Manitoba University, Canada.

Dou, Shuo Zeng, Seikai, T. and Tsukamoto, K. 2000. Cannibalism in Japanese flounder juveniles, Paralichthys olivaceus, reared under controlled conditions. Aquaculture, 182: 149-159. doi.org/10.1016/S0044-8486(99)00256-2.

Folkvord, A. 1991. Growth, survival and cannibalism of cod juveniles (Gadus morhua): effects of feed type, starvation and fish size. Aquaculture, 97 (1): 41-59. doi. org/10.1016/0044-8486(91)90278-F.

Fox, L. R. 1975. Cannibalism in natural populations. Annual Rev. Ecol. Syst., 6: 87-106. doi.org/10.1146/annurev. es.06.110175.000511.

Goldan, O., Popper, D. and Karplus, I. 1997. Management of size variation in juvenile gilthead sea bream (Sparus aurata). I: Particle size and frequency of feeding dry and live food. Aquaculture, 152(1-4): 181-190.

Hecht, T. and Pienaar, A. G. 1993. A review of cannibalism and its implications in fish larviculture. J. World Aquac. Soc., 24: 246-261. doi.org/10.1111/j.1749-7345.1993.tb00014.x.

Hossain, M. A., Sultana, Z., Kibria, A. S. M. and Azimuddin, K. M. 2012. Optimum dietary protein requirement of a Thai strain of climbing perch, Anabas testudineus (Bloch, 1792) fry. Turkish J. Fish. Aquat. Sci. 12: 217-224.

James, R. and Sampath, K. 2004. Effect of feeding frequency on growth and fecundity in an ornamental fish, Betta splendens (Regan). Israeli J. Aquac., Bamidgeh, 56(2): 136-145.

Katavic, I., Glamuzina, B. and Jug-dujakovic, J. 1989. Cannibalism as a factor affecting the survival of intensively cultured seabass (Dicentrarchus labrax) fingerlings. Aquaculture, 77(2-3): 135-143. doi.org/10.1016/0044-84 86(89)90197-X.

Kentouri, M. 1980. Rearing of larvae of seabass (Dicentrarclllls labrax) using frozen zooplankton organisms: preliminary results. Aquaculture, 21: 171-180.

Kumar, K., Kumar, R., Mohanty, U. L., Saurav, S., Sahoo, M., Mohanty, A. K., Sahu, A. K. and Jayasankar, P. 2012. Climbing perch, Anabas testudineus: Consumer delicacy. Fishing Chimes, 32(6): 40-44.

Kumar, K., Sarma, S., Chakrabarti, P. P., Kumar, R., Mohanty, U. L., Sahoo, M., Mohanty, A. K., Sahu, A. K. and Jayasankar, P. 2013a. Anabas (koi) farming in Sonapur, Assam, A successful demonstration. Fishing Chimes, 33(1\&2): 136-137.

Kumar, K., Lalrinsanga, P. L., Sahoo, M., Mohanty, U. L., Kumar, R. and Sahu, A. K. 2013b. Length-weight relationship and condition factor of Anabas testudineus and Channa species under different culture systems. World J. Fish Mar. Sci., 5: 74-78.

Kumar, K., Mohanty, U., Kumar, R., Damle, D., Noor Jahan, Jena, J. K. and Eknath, A. E. 2012. Aquac. Asia, XVII (3): 27-28.

Lovell, R. T. and Stickney, R. R. 1977. Nutrition and feeding of Channel catfish. Southern Cooperative Series Bulletin, $218 \mathrm{pp}$.

Mandal, B., Kumar, R. and Jayashankar, P. 2016. Efficacy of exogenous hormone (GnRHa) for induced breeding of climbing perch (Anabas testudineus) and influence of operational sex ratio on spawning success. Anim. Reprod. Sci., 171: 114-120. doi: 10.1016/j.anireprosci.2016.06.006.

Marte, C. L, Nocillado, J. and Borlongan, I. 1991. Improved survival and growth of milk fish (Chanos chanos) larvae reared on high HUFA containing larval feeds as supplement to live feed. Proceedings of thr $3^{\text {rd }}$ Asian Fisheries Forum, $189 \mathrm{pp}$.

Meer, M. B., Zamora, J. E. and Verdegem, M. C. I. 1997. Effect of dietary lipid level on protein utilisation and the size and proximate composition of body compartments of Colossoma macropomum (Cuvier). Aquac. Res., 28: 405-17. doi.org/10.1046/j.1365-2109.1997.00873.x.

Miki, T., Nakatsukasa, H., Takahashi, N., Murata, O. and Ishibashi, Y. 2011. Aggressive behaviour and cannibalism in greater amberjack, Seriola dumerili: effects of stocking density, feeding conditions and size differences. Aquac. Res., 42: 1339-1349. doi.org/10.1111/j.1365-2109.2010. 02722.x.

Mookerjee, H. K. and Mazumdar, S. R. 1946. On the life history, breeding and rearing of Anabas testudineus (Bloch). J. Dep. Sci. Calcutta Univ., 2: 101-140.

Polis, G. A. 1981. The evolution and dynamics of intraspecific predation. Annual Rev. Ecol. Syst., 12: 225-251. doi.org/10.1146/annurev.es.12.110181.001301.

Potongkam, K. 1972. Experiment on feeding climbing perch, Anabas testudenius (Bloch) with ground trash fish and pellets. Department of Fisheries Annual Report, Bangkok, Thailand.

Sarkar, U. K., Deepak, P. K., Kapoo, D., Negi, R. S., Paul, S. K. and Singh, S. 2005. Captive breeding of climbing perch Anabas testudineus (Bloch, 1792) with Wova FH for conservation and aquaculture. Aquac. Res., 36(10): 941-945. doi.org/10.1111/j.1365-2109.2005.01281.x.

Smith, P. L. 1979. The development of a nursery technique for rearing turbot Scophthalmus maximus, from the metamorphosis to on growing size progress since 1970 by the British White Fish authority. In: Pillay, T.V.R. and Wm. A. Dill (Eds,), Advances in aquaculture, Fishing News Books, p. 143-149. 
Watanabe, T., Kitajima, C. and Fujita, S. 1983. Nutritional value of live organisms used in Japan for mass propagation of fish: a review. Aquaculture, 34: 115-143.
Zalina, I., Saad, C. R., Christianus, A. and Harmin, S. A. 2012. Induced breeding and embryonic development of climbing perch (Anabas testudineus, Bloch). J. Fish. Aquat. Sci., 7(5): 291-306. DOI: 10.3923/jfas.2012.291.306. 